\title{
Research Help-Seeking in Residents of Ophthalmology in Mashhad University of Medical Sciences: A Cross-Sectional Study
}

\author{
Hasan Gholami $\mathbb{D}^{1},{ }^{1}$ Seyed Masoud Hosseini $\mathbb{D C}^{1}{ }^{1}$ Talieh Saeidi Rezvani $\mathbb{D}^{2}{ }^{2}$ \\ Ghodsieh Zamani $\mathbb{B}^{3},{ }^{3}$ and Mojtaba Abrishami $\mathbb{1}^{3}$ \\ ${ }^{1}$ Department of Medical Education, Faculty of Medicine, Mashhad University of Medical Sciences, Mashhad, Iran \\ ${ }^{2}$ Department of Education and Psychology, Ferdowsi University of Mashhad, Mashhad, Iran \\ ${ }^{3}$ Eye Research Center, Mashhad University of Medical Sciences, Mashhad, Iran \\ Correspondence should be addressed to Mojtaba Abrishami; mojtaba_abrishami@yahoo.com
}

Received 17 October 2021; Revised 31 December 2021; Accepted 4 January 2022; Published 17 January 2022

Academic Editor: Ehsan Namaziandost

Copyright (c) 2022 Hasan Gholami et al. This is an open access article distributed under the Creative Commons Attribution License, which permits unrestricted use, distribution, and reproduction in any medium, provided the original work is properly cited.

\begin{abstract}
Background and Objectives. Considering the undeniable role of the help-seeking strategy in learning research skills, this study aimed to examine the situation of research help-seeking among ophthalmology residents of Mashhad University of Medical Sciences (MUMS), Mashhad, Iran. Materials and Methods. This descriptive cross-sectional study was performed on all ophthalmology residents of MUMS $(n=46)$. A validated research help-seeking scale was used to collect the required data. The scale consisted of 29 items and assessed the three dimensions of avoidance of help-seeking, adaptive help-seeking, and perceived benefit of help-seeking. The answers were scored based on a six-point Likert scale. Results. In total, 41 residents who responded to the electronic version of the research help-seeking scale were selected through convenience sampling. In the axes of help-seeking avoidance and perceived benefit of help-seeking, indexes were in the upper-middle level, while in the adaptive help-seeking axis, it was in the lower-middle level. Based on the results, gender and academic year of residency had no effect on research help-seeking aspects in the participants. However, age had a positive and significant correlation with the perceived benefit of help-seeking. Conclusion. Research help-seeking in residents of ophthalmology of MUMS in all three axes was around the middle level, and it is recommended that university officials and professors encourage residents use adaptive help-seeking strategy during their residency to improve their research skills.
\end{abstract}

\section{Introduction}

The medical education system is one of the most important subsectors in the higher education system of any country. In this sector, appropriate research in accordance with the needs of society is very significant due to its effective role in identifying educational, research, and health problems as well as maintenance of public health [1]. In other words, providing information, guiding projects, implementing programs and policies related to health, and researching in the field of health and medicine play important roles in the promotion of community health and lead to the evolution of health systems [2].

Accordingly, one of the main goals of the medical education program is to train students as qualified researchers who have acquired the knowledge and skills needed for the conduction of research and publication of research results in a specific field of study $[3,4]$. However, many medical students are less inclined to perform clinical research and have poor basic knowledge and skills to conduct research [5-8].

The help-seeking strategy helps the researcher to use the skills required in each of the steps of research in a desirable way [9]. Help-seeking is a reflection of the theory of learning of Vygotsky and self-regulated learning theory. In his theory of learning, Vygotsky introduces the zone of proximal development, which refers to those activities that are above the current knowledge and skills of the learner. In this theory, learners should be trained to acquire skills and solve 
problems with the help of others [10]. According to selfregulated learning theory, one of the characteristics of a selfregulated learner is how to use others as a source to resolve their ambiguities and problems [11].

Research help-seeking is considered a strategy to overcome research barriers; in the face of difficult problems that cannot be solved while researching, the researcher uses all significant elements of this strategy to conduct the research effectively [12].

Research has shown the importance of the application of research help seeking in the field of research, including Beisler and Medaille study who have shown that students who seek appropriate help from others in doing research assignments have better research and writing habits, and use this strategy with a special conscience; Prodigal students, on the other hand, do not spend enough time getting help [13]. Colvin's study also showed that the attitude towards helping has a positive and significant relationship with self-efficacy and progress in the dissertation [14]. Mbato and Cendra state that encouraging and supporting students and combining research activities with medical students' educational activities play an important role in filling the gap between research physicians and affect the development of knowledge and research [15].

Other research in this area shows that help-seeking is an effective strategy for acquiring knowledge and learning research skills and, as a self-monitoring strategy, is closely related to academic success and achievement of scientific and research objectives [13-16].

Regarding the factors affecting help-seeking, the results of some studies indicate that demographic characteristics, such as age, gender, level of education, and field of study influence help-seeking $[17,18]$. However, based on the results of some other studies, demographic factors do not affect it $[19,20]$. Although help-seeking plays an important role in the promotion of research and professional skills of medical students, there are no studies about the status of research help-seeking in the community of residents. Moreover, the existing data regarding the effect of demographic factors on help-seeking are contradictory in the reviewed literature. Accordingly, the present study aimed to investigate the status of research help-seeking in a group of specialty training students, ophthalmic residents of Mashhad University of Medical Sciences (MUMS), Mashhad, Iran.

\section{Materials and Methods}

2.1. Study Participants. The statistical population of this descriptive survey study research was all ophthalmic residents of MUMS $(n=46)$ who were studying in the first semester of the academic year 2020-2021. The sample size was determined by Krejcie and Morgan table as 41. Accordingly, 41 residents of ophthalmology who responded to the electronic version of the research help-seeking scale were selected through convenience sampling.

2.2. Instrument. A validated research help-seeking scale was used to collect the required data. This scale consisted of 29 items and assessed the three dimensions of the avoidance of help-seeking, adaptive help-seeking, and perceived benefit of help-seeking. The answers were scored based on the fivepoint Likert scale ranging from 1 (totally disagree) to 5 (totally agree). In this scale, the scores of each component are calculated separately, and the scale has no total score.

The validity of this tool was examined and confirmed in a study [12] conducted on the student community of Ferdowsi University of Mashhad using content validity, exploratory factor analysis, and convergent validity. Evidence for the convergent validity of the scale showed a positive and significant relationship between the scores of the scale and the academic help-seeking scale $(P<0.001, r=0.25)$.

Regarding its reliability, Cronbach's alpha coefficient of the whole scale was calculated at 0.88 , and the Cronbach's alpha values of the subscales were reported between 0.86 and 0.93 , indicating the reliability of the subscales as well as the whole scale. The psychometric properties of this scale were studied for the first time in a study [21] performed in the medical community.

Content validity, as well as exploratory and confirmatory factor validity, was used to examine the validity of the scale, and the reported results were desirable. Results of exploratory factor analysis by principal component method with varimax rotation revealed three factors. This finding was somewhat different from that of a previous study in which this scale was evaluated [12]. Therefore, in the new factor structure, the need for help-seeking was eliminated. Moreover, items 11 and 12 were eliminated due to the common factor load under two factors, while items $1,7,8$, 14 , and 27 were eliminated due to the factor load less than 0.4. In the abovementioned study, Cronbach's alpha for each subscale ranged from 0.74 to 0.91 .

2.3. Statistical Analysis. In order to assess the current situation of Residents of Ophthalmology in research help seeking, minimum, maximum, and average descriptive statistics indices were used. In this way, the score range of each of the components of research help seeking (avoidance of help-seeking, adaptive help-seeking, and perceived benefit of help seeking) was determined and divided into four parts: low level, lower-middle level, upper-middle level, and high level. Then, according to the average position in the mentioned spectrum, the current situation of research help seeking in Residents of Ophthalmology was examined.

Multivariate analysis of variance (MANOVA) and Pearson correlation were used to investigate the effect of gender and the year of study on help-seeking components, respectively. Before the conduction of a MANOVA, the assumptions of normal distribution of variables, variancecovariance matrix homogeneity, and correlation of dependent variables were confirmed. Analyses were performed in SPSS software (version 26).

2.4. Ethical Considerations. The study protocol adhered to the tenets of the Declaration of Helsinki. Informed consent was obtained from all participants before enrollment. Moreover, the ethical aspects of the study were approved by 
the Regional Committee on Medical Ethics at MUMS, Mashhad, Iran (IR.MUMS.MEDICAL.REC.1399.196).

\section{Results}

Based on the demographic characteristics of the samples, the mean age of the whole sample was $30.34 \pm 2.87$. The mean age of female and male participants was $30.32 \pm 2.68$ and $30.37 \pm 2.96$, respectively. The majority of the participants were year residents $(36.6 \%)$, and $53.7 \%$ of the total sample were women. In Table 1, the sample distribution by gender and the year of residents is presented.

Research help-seeking axes evaluation in residents of ophthalmology showed that the average of the avoidance of help-seeking, adaptive help-seeking, and perceived benefit of help seeking were $13.44,22.21$, and 12.51 , respectively. In general, the status of residents of ophthalmology in the avoidance of help-seeking and perceived benefit of help seeking was in the upper-middle level and that in adaptive help-seeking was in the lower-middle level (Table 2).

In gender evaluation on the research help-seeking components, the results of multivariate analysis of variance showed that the linear combination of variables did not differ significantly between groups $(P=0.584, F=0.65$, Wilks' lambda $=0.95$ ) (Table 3 ) and the years of residents $(P=0.584, F=37.84$, Wilks' lambda $=0.68)($ Table 4$)$.

The study of the relationship between age and research help-seeking components showed that there was a positive and significant relationship between the perceived benefit of help-seeking and the age of the residents of ophthalmology at MUMS $(P \geq 0.05, r=0.35)$. Therefore, there is a mutual relationship between age and the perceived benefit of research help-seeking. In addition, there was a negative relationship between the avoidance of help-seeking and age which was statistically insignificant (Table 5).

\section{Discussion}

This study aimed to investigate the status of research helpseeking in residents of ophthalmology and the effect of demographic variables on it. The study of the status of research help-seeking showed that residents were in the uppermiddle level regarding avoidance of help-seeking and perceived benefit of help-seeking. It also indicated that they are in the lower-middle level regarding adaptive help-seeking.

In some previous studies, adaptive help-seeking is associated with high levels of self-regulation [22-24]. Accordingly, regarding the lower-middle level in adaptive help-seeking in residents in this study, it can be said that a defect in self-regulation skills in residents is one of the possible reasons for the lower level of adaptive help-seeking in them.

The university can play an effective role in the promotion of research self-regulation skills of residents by emphasizing the research process and research skills of residents instead of emphasizing research performance and also teaching them how to use self-regulation in research. In addition, consistent with the study [25], other possible reasons for the low level of adaptive help-seeking of residents include the lack of mastery of help-seeking skills and, consequently, inability to seek help.

Based on Newman's theory [26], the necessary abilities for having adaptive help-seeking include cognitive ability, social ability, individual motivational resources, and external motivational sources. Accordingly, consistent with a previous study [6], the university is obliged to equip them with the necessary cognitive and social abilities to seek help through the necessary training and, in this way, gradually turn them into independent researchers.

To explain the upper-middle level position of residents regarding the perceived benefit of help-seeking and avoidance of help-seeking, it can be said that despite the value they put on help-seeking, residents avoid it for various reasons. In general, various psychological factors, such as feelings of embarrassment and shyness, a sense of threat to one's selfesteem, unwillingness to reveal problems and inefficiencies, fear of negative perceptions of others, willingness to perform independently, fear of the unwillingness of others to help them, and the lack of competent helpers, can be the reasons why learners are reluctant to ask for help [26, 27].

According to the hypothesis of vulnerability in the theory of self-respect, the act of seeking help indicates inferiority and, therefore, threatens one's self-respect. Based on this hypothesis, people who seek help acknowledge their inferiority and put their dignity at risk [28]. Accordingly, one of the possible reasons for the avoidance of help-seeking by residents in the field of research is related to their perception of the threat of help-seeking. This can lead to their poor performance in research activities, whereas if residents consider help-seeking as a necessary part of research activities and not a threat to themselves, their interest in research activities will increase and they will not be afraid to enter the difficult path of research.

In addition, consistent with previous studies [24, 29, 30], one of the possible reasons for avoiding help-seeking is the low sense of belonging to university in residents. A sense of belonging, defined as a sense of belonging or connectedness to others and one's own community, is a fundamental psychological need. Lack of acceptance of individuals into social groups is the most influential factor that leads to feelings of inadequacy, guilt, and anxiety [31].

If students feel accepted and respected by professors and others, they feel less threatened by help-seeking and are not afraid to ask for help when they need it $[15,24]$. Therefore, students' perception of the social context is an important determinant of their help-seeking. Many studies have found the importance of students' perception of social context and help-seeking, including a study [32] whose results revealed that the positive interaction between the help-seeker and the helper increases the likelihood of seeking help.

In this regard, the results of another study [16] also indicated the role of social support of professors and universities in encouraging students to research help-seeking. Therefore, if the residents feel that they are an important and valuable member of their university and are supported and accepted by the professors and the university, they will be more inclined to seek help when they need it. Accordingly, the university is obliged to encourage students to use help- 
TABle 1: Demographic distribution of the sample by gender and residents of different academic years.

\begin{tabular}{lcccc}
\hline Variable & Group & Frequency & Valid percent & Cumulative percent \\
\hline \multirow{4}{*}{ Residents of different academic years } & First & 8 & 19.50 & 19.50 \\
& Second & 9 & 22 & 41.50 \\
& Third & 9 & 22 & 63.40 \\
Gender & Fourth & 15 & 36.60 & 100 \\
& Male & 19 & 46.30 & 100 \\
\hline
\end{tabular}

TABLE 2: The status of research help-seeking in residents of ophthalmology.

\begin{tabular}{lcccccc}
\hline Constructs & Low level & Lower-middle level & Upper-middle level & High level & Mean \pm SD & Current situation \\
\hline Avoidance of help-seeking & $0-8$ & $8-12$ & $12-17.50$ & $17.50-55$ & $13.44 \pm 9$ & Upper-middle level \\
Adaptive help-seeking & $0-19.50$ & $19.50-23$ & $23-25$ & $25-35$ & $22.21 \pm 4.59$ & Lower-middle level \\
Perceived benefit of help seeking & $0-11.50$ & $11.50-12$ & $12-14.50$ & $14.50-15$ & $12.51 \pm 1.87$ & Upper-middle level \\
\hline
\end{tabular}

TABLE 3: Multivariate analysis of variance test results of the difference between male and female in the research help-seeking subscale table.

\begin{tabular}{lcccrr}
\hline Source & Wilks' lambda & $F$ & Hypothesis df & Error df & $P$ \\
\hline Gender & 0.95 & 0.65 & 3 & 37 & $P \geq 0.05$ \\
\hline
\end{tabular}

TABLE 4: Multivariate analysis of variance test results of the difference between residents of different academic years in the research helpseeking subscale table.

\begin{tabular}{lccccc}
\hline Source & Wilks' lambda & $F$ & Hypothesis df & Error df & $P$ \\
\hline Residents of different academic years & 0.82 & 0.81 & 9 & 85.33 & $P \geq 0.05$ \\
\hline
\end{tabular}

TABLE 5: Correlation coefficients between age and research helpseeking subscale.

\begin{tabular}{lc}
\hline Variable & Age \\
\hline Avoidance of help-seeking & -0.21 \\
Adaptive help-seeking & 0.03 \\
Perceived benefit of help seeking & $0.35^{*}$ \\
\hline
\end{tabular}

${ }^{*} P \leq 0.05$.

seeking strategies by creating a supportive, caring, and receptive atmosphere.

Based on the findings of some previous studies [15, 24], it can be said that another possible reason for the uppermiddle-level of help-seeking avoidance and the lowermiddle-level of adaptive help-seeking in residents is related to the value that students place on research activities. In this regard, students state that they are more likely to turn to adaptive help-seeking when they find learning assignments useful and valuable to their lives and careers.

According to the results of the research $[33,34]$ conducted in this field, perception of the high value of a task has a positive relationship with adaptive help-seeking and a negative and significant relationship with the avoidance of help-seeking. Accordingly, if students, in addition to the value they place on educational activities, become aware of the need for research, they will use the help-seeking strategy with the goal of success in research activities.

Comparison of each component of research help-seeking in male and female residents revealed that there was no significant difference between the two groups in terms of research help-seeking aspects. This finding is consistent with those of previous studies $[19,20]$ which indicated that there is no significant relationship between gender and academic help-seeking. However, this result is inconsistent with those of previous studies $[15,35,36]$ which showed that female students are more likely inclined to use adaptive helpseeking. It seems that the role of other demographic variables should be considered in explaining gender differences.

Comparison of each component of research help-seeking in residents in different years of study showed that there is no significant difference between the four groups in terms of research help-seeking aspects. This finding is inconsistent with that of a study performed by McClure [18] which revealed that students in higher levels of education are more likely to seek help.

One of the reasons for the lack of difference in helpseeking components in residents in different years of study can be related to the limited period of specialization course. This means that, due to the closeness of the experience of residents in the specialization course, there is no difference in their research help-seeking. In addition, this finding can be explained through Bandura's cognitive-social theory. As mentioned, help-seeking behavior is one of the selfregulation strategies, as one of the characteristics of a self-regulated learner is how to use others as a source to resolve their ambiguities and problems. This theory considers self-regulation as the interaction among personal, environmental, and behavioral factors. Accordingly, research help-seeking is not a skill that can be acquired spontaneously by passing to a higher year of 
study. Given that the statistical population of this study was specialist residents of ophthalmology of Mashhad University of Medical Sciences, this population is a homogeneous community. Therefore, due to the homogeneity of the statistical population, environmental factors naturally are not very different among residents of different academic years.

The results of the study regarding the relationship between age and components of research help-seeking showed a positive and significant relationship between the perceived benefit of help-seeking and the age of residents of ophthalmology of Mashhad University of Medical Sciences. Accordingly, there was a mutual relationship between the age of subjects and the perceived benefit of research helpseeking. This finding is consistent with those of a previous study [37] in which the researcher found that as they become older, people are more likely to turn to help-seeking. The reason is that metacognitive skills increase with age and people are better able to monitor their performance and use adaptive help-seeking.

In this regard, Perrine et al. [38] also found that younger students were less likely to turn to help-seeking due to their lower awareness of the usefulness and application of helpseeking in learning, especially when they consider helpingseeking as a threat to their abilities.

There are some limitations to the present study that require consideration. At first, since the results of this study were not retested to assess stability over time, they should be generalized with caution. In addition, data gathering from questionnaires may have introduced a level of bias, as it may be biased towards positive attitudes. Furthermore, we did not investigate actual help-seeking behaviour; it is possible that positive help-seeking attitudes and intentions do not translate into action. So, we suggest further studies that measure help-seeking behaviour.

Overall, the present findings provide some evidence that students need interventions that increase their help-seeking attitudes. Significantly, however, very little is known about what interventions increase help-seeking behaviour. Further research underpinned by models of help-seeking which facilitate the design of interventions are required if we want train students as qualified researchers. In total, it is suggested that a model be designed for research help-seeking training to increase the research skills of ophthalmic residents. In addition, it is recommended that university officials and professors encourage residents to use adaptive help-seeking during the residency course and inform them that helpseeking can improve their skills to conduct their scientific research with more knowledge and achieve more success in this regard. Finally, since available sampling was used in this study due to the prevalence of COVID-19 epidemic, it is suggested that random sampling, which is more representative of the statistical population, be used in future studies.

\section{Data Availability}

The datasets generated and analyzed during the current study are available from the corresponding author on reasonable request.

\section{Ethical Approval}

The study protocol adhered to the tenets of the Declaration of Helsinki. The ethical aspects of the study were approved by the Regional Committee on Medical Ethics at Mashhad University of Medical Sciences, Mashhad, Iran (IR.MUMS.MEDICAL.REC.1399.196).

\section{Consent}

All participants provided informed consent before enrollment.

\section{Disclosure}

This work was a part of Master of Medical Education thesis of Dr. Mojtaba Abrishami.

\section{Conflicts of Interest}

The authors declare that they have no conflicts of interest.

\section{Authors' Contributions}

All the authors contributed significantly to this study, and all authors agree to be accountable for all aspects of the work. All authors read and approved the final manuscript. All named authors meet the International Committee of Medical Journal Editors (ICMJE) criteria for authorship for this article, take responsibility for the integrity of the work as a whole, and have given their approval for this version to be published.

\section{Acknowledgments}

The authors would like to thank Raheleh Gharibnavaz, Nayyereh Hoshyar, Shima zarifnahad, and personnel of the medical education department. The authors also acknowledge the kind support of Mohammad Javad Razmjoo. The authors would like to acknowledge the financial support of the Vice-Chancellor of Research of Mashhad University of Medical Sciences for this research project (code: 980553).

\section{References}

[1] R. Salem Safy, N. Ashraf Rezaei, R. Sadatian, Z. Moshirie, N. Sheikhy, and A. Baniadam, "Study of views of faculty members about research barriers in Urmea University of medical sciences," Journal of Faculty Nursing and Midwifery of Urmea University, vol. 7, no. 3, pp. 142-150, 2009.

[2] H. Babamohamadi, F. Deihim Far, H. Chaharpashlo, M. Hamidi, and M. Kahouei, "The approach and function of university students to research process: a cross sectional study," Koomesh Journal, vol. 19, no. 2, pp. 412-420, 2017.

[3] A. Abu-Zaid and K. Alkattan, "Integration of scientific research training into undergraduate medical education: a reminder call," Medical Education Online, vol. 18, no. 1, p. 22832, 2013.

[4] L. Ribeiro, M. Severo, and M. A. Ferreira, "Performance of a core of transversal skills: self-perceptions of undergraduate medical students," BMC Medical Education, vol. 16, no. 1, p. 18, 2016. 
[5] A. Ibrahim Abushouk, A. Nazmy Hatata, I. Mahmoud Omran, M. Mahmoud Youniss, K. Fayez Elmansy, and A. Gad Meawad, "Attitudes and perceived barriers among medical students towards clinical research: a cross-sectional study in an Egyptian medical school," Journal of Biomedical Education, vol. 2016, Article ID 5490575, 7 pages, 2016.

[6] A. Laidlaw, J. Aiton, J. Struthers, and S. Guild, "Developing research skills in medical students: AMEE Guide No. 69," Medical Teacher, vol. 34, no. 9, pp. 754-771, 2012.

[7] M. S. Mazloomy, S. Hosseini, S. M. Abbasi, A. M. Mirzaei, and F. Rezaei, "A survey of Shahid Sadoughi University of Medical Sciences students opinion about research barriers during university training," Journal of Medical Education Development, vol. 6, no. 10, pp. 63-70, 2013.

[8] A. Saeidinia, M. Karkan, A. Heidarzadeh, N. Taeifeh, and N. Porkar, "Knowledge, attitude and practice of Guilan University of medical sciences toward research," Annals of Biological Research, vol. 4, pp. 89-94, 2013.

[9] T. S. M. Meerah, "Readiness of preparing postgraduate students in pursuit of their doctoral programme," ProcediaSocial and Behavioral Sciences, vol. 9, pp. 184-188, 2010.

[10] V. Aleven, E. Stahl, S. Schworm, F. Fischer, and R. Wallace, "Help seeking and help design in interactive learning environments," Review of Educational Research, vol. 73, no. 3, pp. 277-320, 2003.

[11] B. Zimmerman, Handbook of Self-Regulation of Learning and Performance, Routledge, London, UK, 2011.

[12] H. Kareshki and E. Hejazi, "Factor structure and psychometric properties of the index of help-seeking behavior in the research process of college students," Transylvanian Review, vol. 1, no. 4, 2017.

[13] M. Beisler and A. Medaille, "How do students get help with research assignments? Using drawings to understand students' help seeking behavior," The Journal of Academic Librarianship, vol. 42 , no. 4, pp. 390-400, 2016.

[14] T. S. Colvin, The Role of Academic Help-Seeking Attitudes, Achievement Goal Orientations, and Dissertation Self-Efficacy in Dissertation Progress, The University of Memphis, Memphis, TN, USA, 2012.

[15] C. L. Mbato and A. Cendra, "EFL undergraduate students' self-regulation in thesis writing: help-seeking and motivationregulation," JELE (Journal of English Language and Education), vol. 5, no. 1, pp. 66-82, 2019.

[16] A. Oluwakemi, "Academic locus of control and social support as predictors of research help-seeking behaviour among Nigerian undergraduates," American Journal of Psychology and Cognitive Science, vol. 1, no. 2, pp. 29-36, 2015.

[17] H. Kareshki, T. saeidi, and E. Hejazi, "Research help seeking situation among students of Ferdowsi university of Mashhad," Educational Research Journal, vol. 4, no. 3, pp. 93-110, 2017.

[18] A. K. McClure, Help-Seeking Attitudes and Behaviors of Graduate Psychology Students, Florida State University, Tallahassee, FL, USA, 2014.

[19] H. Marrs, E. A. Sigler, and R. D. Brammer, "Gender, masculinity, femininity, and help seeking in college," Masculinities \& Social Change, vol. 1, no. 3, pp. 267-292, 2012.

[20] A. M. Ryan and P. R. Pintrich, “"Should I ask for help?" the role of motivation and attitudes in adolescents' help seeking in math class," Journal of Educational Psychology, vol. 89, no. 2, pp. 329-341, 1997.

[21] M. Abrishami, H. Gholami, and M. Hosseini, Psychometric Properties of the Research Help-Seeking Scale and Evaluation of Its Components in Ophthalmology Resident at Mashhad
University of Medical Sciences, Mashhad University of Medical Sciences, Mashhad, Iran, 2021.

[22] K. E. Dunn, G. C. Rakes, and T. A. Rakes, "Influence of academic self-regulation, critical thinking, and age on online graduate students' academic help-seeking," Distance Education, vol. 35, no. 1, pp. 75-89, 2014.

[23] S. J. Finney, C. L. Barry, S. Jeanne Horst, and M. M. Johnston, "Exploring profiles of academic help seeking: a mixture modeling approach," Learning and Individual Differences, vol. 61, pp. 158-171, 2018.

[24] S. Won, L. C. Hensley, and C. A. Wolters, "Brief research report: sense of belonging and academic help-seeking as selfregulated learning," The Journal of Experimental Education, vol. 89, no. 1, pp. 112-124, 2021.

[25] D. Eisenberg, E. Golberstein, and S. E. Gollust, "Help-seeking and access to mental health care in a university student population," Medical Care, vol. 45, no. 7, pp. 594-601, 2007.

[26] R. S. Newman, "How self-regulated learners cope with academic difficulty: the role of adaptive help seeking," Theory into practice, vol. 41, no. 2, pp. 132-138, 2002.

[27] I. Roll, V. Aleven, B. M. McLaren, and K. R. Koedinger, "Improving students' help-seeking skills using metacognitive feedback in an intelligent tutoring system," Learning and Instruction, vol. 21, no. 2, pp. 267-280, 2011.

[28] S. A. Karabenick and J. R. Knapp, "Relationship of academic help seeking to the use of learning strategies and other instrumental achievement behavior in college students," Journal of Educational Psychology, vol. 83, no. 2, pp. 221-230, 1991.

[29] A. M. Ryan, H. Patrick, and S.-O. Shim, "Differential profiles of students identified by their teacher as having avoidant, appropriate, or dependent help-seeking tendencies in the classroom," Journal of Educational Psychology, vol. 97, no. 2, pp. 275-285, 2005.

[30] S. S. Shim, S. M. Kiefer, and C. Wang, "Help seeking among peers: the role of goal structure and peer climate," The Journal of Educational Research, vol. 106, no. 4, pp. 290-300, 2013.

[31] R. M. Ryan and E. L. Deci, Self-determination Theory: Basic Psychological Needs in Motivation, Development, and Wellness, Guilford Publications, New York, NY, USA, 2017.

[32] J. C. Turner, C. Midgley, D. K. Meyer et al., "The classroom environment and students' reports of avoidance strategies in mathematics: a multimethod study," Journal of Educational Psychology, vol. 94, no. 1, pp. 88-106, 2002.

[33] S. A. Karabenick, "Perceived achievement goal structure and college student help seeking," Journal of Educational Psychology, vol. 96, no. 3, pp. 569-581, 2004.

[34] A. Zusho and P. A. Barnett, "Personal and contextual determinants of ethnically diverse female high school students' patterns of academic help seeking and help avoidance in English and mathematics," Contemporary Educational Psychology, vol. 36, no. 2, pp. 152-164, 2011.

[35] F. Pajares, Y. F. Cheong, and P. Oberman, "Psychometric analysis of computer science help-seeking scales," Educational and Psychological Measurement, vol. 64, no. 3, pp. 496-513, 2004.

[36] J. V. McGee, Cognitive, Demographic, and Motivational Factors as Indicators of Help-Seeking in Supplemental Instruction, Texas A\&M University, College Station, TX, USA, 2005.

[37] S. N.-L. Gall, "Help-seeking: an understudied problemsolving skill in children," Developmental Review, vol. 1, no. 3, pp. 224-246, 1981.

[38] R. M. Perrine, J. Lisle, and D. L. Tucker, "Effects of a syllabus offer of help, student age, and class size on college students' willingness to seek support from faculty," The Journal of Experimental Education, vol. 64, no. 1, pp. 41-52, 1995. 